\title{
SCOUR MECHANISM INDUCED BY PROPELLER FLOW NEAR A QUAY WALL
}

\author{
Yalcin Yuksel, Yıldız Technical University, yalcinyksl@gmail.com \\ llayda Tan, Yıldız Technical University, rilaydatan@gmail.com \\ Yesim Celikoglu, Yıldız Technical University, celikogluyesim@gmail.com \\ Taha Atik, Yıldız Technical University, tahaatik2210@gmail.com
}

\begin{abstract}
INTRODUCTION
Increasing ship dimensions in recent years cause structural instability due to the scouring problem during berthing and unberthing maneuver of the vessels.

The propeller jet has 3D flow area and high velocities that may cause erosion problem around the berthing structures in three ways. These are; a) On a slope, b) At the toe of vertical wall, c) Around piles.

In general scour problems are investigated by using physical modeling. Propeller jet induced the scour in front of the wall has been well studied in the past (Hamill et al. (1999), Ryan et al. (2013(a)), Ryan et al. (2013(b))).

In this study, propeller jet flow was considered to investigate the seabed scour mechanism with and without vertical quay wall conditions and their comparisons were made. Three different distances of the propeller from the wall at $X_{w}=0.7 \mathrm{~m}, 0.35 \mathrm{~m}$ and $0.175 \mathrm{~m}$ were tested for different clearances at $\mathrm{G}=0.1 \mathrm{~m}$ and $0.15 \mathrm{~m}$ on sand bed of $d_{50}=0.052 \mathrm{~mm}$ to give an extensive definition for scour depth estimation.
\end{abstract}

\section{EXPERIMENTAL SETUP}

The experiments were conducted in a flume to simulate propeller jet flow conditions on unprotected sand bed for both confined with quay wall and unconfined conditions. Sides of the working section in the flume was made of glass with total length of $6.05 \mathrm{~m}$, width of $1.42 \mathrm{~m}$ and depth of $1.0 \mathrm{~m}$ in the Hydraulics and Coastal Engineering Laboratory of the Civil Engineering Department at Yıldız Technical University as seen in Figure 1.

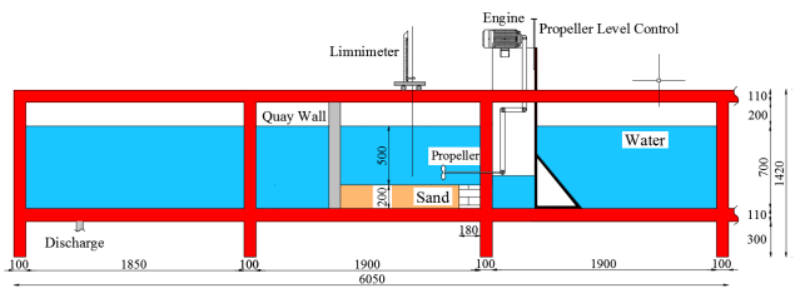

Figure 1 - Schematic layout of experimental setup in millimeter (cross-sectional view)

Propeller was placed on a level controller platform to test different clearances of the propeller with changing velocities. A series of experiments were performed for sand bed material size of $d_{50}=0.52 \mathrm{~mm}$ to understand the scour formations under propeller jet flow for different conditions such as; different clearances, propeller diameters, jet velocities and wall locations. Effects of the existence of the quay wall to the scour mechanism and scour formations were also investigated and compared with unconfined situation.

\section{SCOUR FORMATIONS}

Significant changes were observed on scour formations in case of the presence of a quay wall when compared with the unconfined situation.

Scour developments with time were measured at each test. Figures 2 and 3 show equilibrium scour profiles induced by one of the propeller with diameter of $0.65 \mathrm{~m}$ at $745 \mathrm{rpm}$ for unconfined and confined conditions for the wall distances from the propeller face at $X_{w}=0.7 \mathrm{~m}$ and $0.35 \mathrm{~m}$, respectively. These wall locations were also considered at the deposition and maximum eroded zone for unconfined situation.
Scour depth was greater at the toe of wall when compared with no wall conditions, at the same location. Scour dimensions also, changed with existence of the quay wall as seen in Figures 2 and 3.

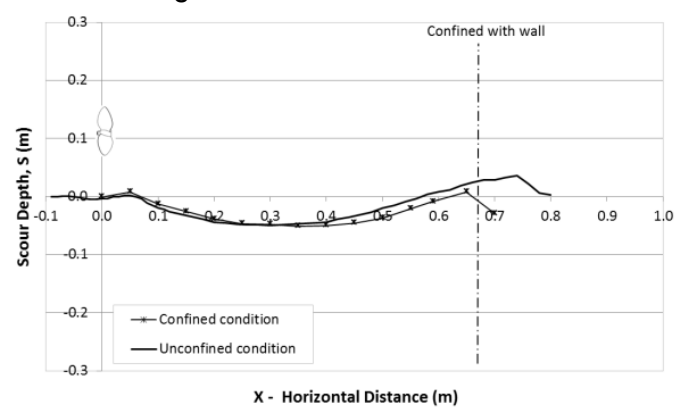

Figure 2 - Scour profile on sand bed $\left(d_{50}=0.52 \mathrm{~mm}\right)$ with a quay wall at $X_{w}=0.7 m$ distance from the face of propeller at equilibrium stage $\left(G=0.1 \mathrm{~m}, D_{p}=0.65 \mathrm{~m}, 745 \mathrm{rpm}\right)$

As seen in Figure 3, test results show that scour depths at the toe of wall increase for the closer wall positions $\left(X_{w}\right)$. These scour depths are always greater than unconfined cases.

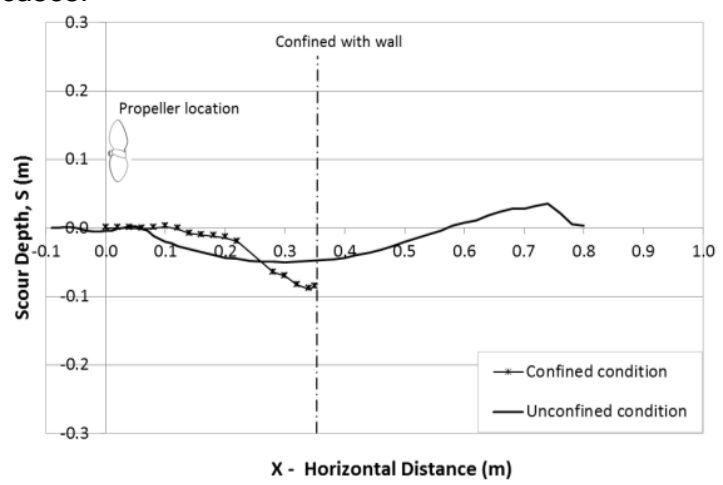

Figure 3 - Scour profile on sand bed $\left(d_{50}=0.52 \mathrm{~mm}\right)$ with a quay wall at $X_{w}=0.35 \mathrm{~m}$ distance from the face of propeller at equilibrium stage $\left(G=0.1 \mathrm{~m}, D_{p}=0.65 \mathrm{~m}, 745 \mathrm{rpm}\right)$

\section{CONCLUSION}

Scour formation depends on propeller diameter, jet velocity, clearance and the distance in between propeller and quay wall location. However new scour formations are also observed which are different from the previous studies.

Existence of perpendicular quay wall causes greater scour depths at the toe of the wall when compared with unconfined conditions for different distances of the wall from the propeller face.

\section{REFERENCES}

Hamill, G. A., Johnston, H., and Stewart, D. (1999): Propeller wash scour near quay walls." J. Waterway, Port, Coastal, Ocean Eng., 10.1061/(ASCE)0733950X(1999)125:4(170), 170-175.

Ryan, D., Eng, C., Hamill, G.A., (2013 (a)): Determining Propeller Erosion at the Stern of a Berthing Ship, Journal of Waterway, Port, Coastal, and Ocean Eng, 139 (4): 247255.

Ryan, D., Hamill, G.A., Johnston, H.T. (2013(b)): Determining Propeller induced Erosion alongside Quay Walls in Harbours using Artificial Neural Networks, Ocean Engineering, 59 142-151. 